\title{
ANÁLISE DA SECAGEM DE CEVADILHA VACARIANA (BROMUS AULETICUS T.) EM LEITO FIXO COM ESCOAMENTO DE AR PARALELO
}

\author{
L. C. de. OLIVEIRA ${ }^{1}$, R. P. de FREITAS ${ }^{1}$, J. C. P. OLIVEIRA ${ }^{2}$, A. R. F de ALMEIDA $^{1 *}$ \\ ${ }^{1}$ Universidade Federal do Pampa - Programa de Pós-Graduação em Engenharia \\ ${ }^{2}$ Empresa Brasileira de Pesquisa Agropecuária - EMBRAPA/Pecuária Sul \\ *e-mail: andre.almeida@unipampa.edu.br
}

\begin{abstract}
RESUMO
Este trabalho teve como objetivo realizar um estudo sobre o processo de secagem de sementes forrageiras de cevadilha vacariana (Bromus auleticus T.) em um secador de leito fixo com fluxo de ar paralelo. Para alcançar este objetivo o trabalho foi dividido nas etapas de caracterização física, fisiológica e físico-química das sementes, e avaliação dos efeitos da variação da temperatura, da velocidade do ar e da altura da bandeja sobre o processo de secagem. Para caracterização física foram analisados a massa específica real, a massa específica bulk, a porosidade do leito estático, a esfericidade e o diâmetro médio da partícula. A análise fisiológica consistiu no estudo da germinação. A caracterização físico-química foi determinada a partir das isotermas de dessorção e análise de umidade. A cinética de secagem foi obtida através do adimensional de umidade livre em função do tempo. Os dados experimentais obtidos no presente estudo mostraram que as condições de secagem podem influenciar significativamente a umidade de armazenamento e a qualidade fisiológica do produto final, refletida nos valores de umidade e germinação das sementes de cevadilha vacariana.
\end{abstract}

\section{INTRODUÇÃO}

Na região sul do Brasil, forrageiras de clima temperado são de suma importância para os sistemas agropastoris, principalmente no que se refere ao suprimento de forragem para os rebanhos durante os meses de inverno. No caso do Rio Grande do Sul (RS), aproximadamente $76 \%$ da área pastoril utilizada na pecuária de corte é coberta por vegetação natural, sendo $8 \%$ desta área melhorada por adubação e sobressemeadura de espécies forrageiras de clima temperado (Nabinger, 2006).

Segundo Oliveira e Moraes (1993), a Cevadilha Vacariana (Bromus auleticus T.) é produtiva, palatável e acessível aos animais devido a suas características bromatológicas.
Sendo assim, a cevadilha é caracterizada como uma forrageira de grande capacidade de produção durante o período de maior carência alimentar do rebanho (outono-inverno) e com boa qualidade de forragem.

Dentro do processo de produção de sementes forrageiras, cuidados devem ser tomados em relação ao armazenamento, que deve ocorrer em níveis de umidade adequados. As sementes provenientes do campo apresentam, em geral, teor de umidade inadequado para um armazenamento. De acordo com Peske (2003), o elevado teor de umidade das sementes, no período compreendido entre a colheita e a secagem, contribui para acelerar o processo deteriorativo em razão da elevada atividade metabólica. Portanto, a secagem destes grãos 
se torna indispensável para o processo. $\mathrm{O}$ termo secagem pode ser definido com a remoção de líquido de um sólido por evaporação. Sendo assim, o material úmido que entra em contato com o ar insaturado sofre uma transferência simultânea de calor e de massa promovendo uma diminuição do conteúdo de umidade do material, e consequentemente a umidificação desse ar.

Além de menor perda por degradação natural, a secagem possibilita um melhor planejamento para colheita. A secagem artificial vem sendo utilizada como uma operação de rotina nas empresas de sementes, principalmente, nos estados da Região Sul do Brasil e, não obstante as vantagens que apresenta, é uma operação de risco, podendo proporcionar danos irreversíveis se realizada sem os conhecimentos e cuidados necessários à preservação da qualidade inicial das sementes (CARVALHO, 1994; MIRANDA et al. 1999). Sendo assim, a secagem é uma ferramenta importante no cultivo de sementes, e seu estudo torna-se fundamental.

É de grande importância na secagem o estudo da relação de umidade do material e a umidade do ar. Essa relação é feita mediante a avaliação de isotermas de sorção, definida segundo Karathanos et al., (1996) como a relação física entre a umidade do material e a umidade relativa correspondente a uma dada temperatura.

Com o que foi exposto anteriormente e visando contribuir para melhores condições de manutenção das propriedades fisiológicas das sementes forrageiras, no que se refere à germinação e umidade final, este trabalho tem como objetivo analisar o efeito da secagem nas sementes de Cevadilha Vacariana (Bromus auleticus T.), a partir de um secador de leito fixo com escoamento de ar paralelo.

\section{MATERIAS E MÉTODOS}

Para a realização deste trabalho, foram utilizadas sementes de Cevadilha Vacariana, da espécie Bromus Auleticus T., fornecidas pela EMBRAPA/Pecuária Sul localizada na cidade de Bagé/RS. Todos os experimentos foram realizados a partir de um mesmo lote de sementes, referente ao ano 2013/2014, com o intuito de garantir um material com as mesmas características físicas e fisiológicas iniciais.

\subsection{Caracterização das Sementes}

A umidade das sementes foi determinada através do método gravimétrico recomendado pela Association of Official Analytical Chemists - AOAC (1997). A massa específica real $\left(\rho_{r}\right)$ foi obtida pela técnica de picnometria gasosa, a massa específica de bulk $\left(\rho_{b}\right)$ através do ensaio de proveta, o peneiramento para determinar o diâmetro médio de sauter $\left(d_{s}\right)$ e medidas dos comprimentos longitudinais, transversais e circunferênciais para determinar o fator de forma esfericidade $(\phi)$. A porosidade do leito estático $(\varepsilon)$ foi determinada pela relação entre a massa específica bulk e a massa específica real, conforme mostra a Equação 1.

$\varepsilon=1-\left(\frac{\rho_{b}}{\rho_{r}}\right)$

Para a caracterização fisiológica foram efetuados testes de germinação $(G)$ seguindo a metodologia recomendada nas Regras para Análise de Sementes, propostas pelo Ministério da Agricultura, Pecuária e Abastecimento - MAPA/ACS (2009). Esta análise constituiu na utilização de caixas gerbox juntamente com papel filtro embebecido em água, onde foram distribuídas 100 sementes. As amostras foram submetidas a um confinamento controlado em uma germinadora, operando na temperatura de $20{ }^{\circ} \mathrm{C}$ na influência de luz solar natural. As contagens das plântulas procederam no $10^{\circ} \mathrm{e}$ $21^{\circ}$ dia após o início do teste.

A caracterização físico-química foi determinada a partir das isotermas de 
dessorção pelo método gravimétrico estático, utilizando-se soluções de ácido sulfúrico em onze diferentes concentrações que garantiram a variação da umidade relativa do ar de 5 a $89 \%$. Os experimentos foram conduzidos nas temperaturas de 40,50 e $60{ }^{\circ} \mathrm{C}$. Cada análise foi realizada em triplicata, utilizando-se recipientes de vidros hermeticamente fechados, suporte e cadinho de plástico. No interior de cada recipiente foram inseridos $30 \mathrm{~mL}$ das soluções de ácido sulfúrico. Também foi inserido em cada cadinho plástico aproximadamente $1 \mathrm{~g}$ de sementes de cevadilha vacariana.

Os recipientes de vidro foram colocados em estufa de circulação forçada nas temperaturas de estudo, sendo realizadas pesagens do cadinho plástico no primeiro, sétimo, décimo e décimo quarto dia de experimento. Essas pesagens foram feitas com o objetivo de verificar o equilíbrio mássico para cada atmosfera estudada. Com o equilíbrio mássico alcançado, determinou-se a umidade em base úmida $\left(U_{B U}\right)$ e a umidade em base seca $\left(U_{B S}\right)$ das sementes através do método gravimétrico recomendado pela AOAC (1997). Os resultados obtidos nas isotermas foram analisados através do ajuste dos dados experimentais aos modelos de BET, GAB, Oswin, Peleg e Hederson, em substituição das Equações 2 a 6 respectivamente, através de um programa computacional.

$X_{e}=\left[\frac{\left(X_{m} \cdot c \cdot a_{w}\right) \cdot\left[1-\left(n_{1}+1\right) \cdot a_{w}{ }^{n_{1}}+n_{1} \cdot a_{w}{ }^{n_{1}+1}\right]}{\left(1-a_{w}\right) \cdot\left[1-(1-c) \cdot a_{w}-c \cdot a_{w}{ }^{n_{1}+1}\right]}\right]$

$X_{e}=\frac{X_{m} \cdot C t \cdot K \cdot a_{w}}{\left(1-K \cdot a_{w}\right) \cdot\left(1-K \cdot a_{w}+C t \cdot K \cdot a_{w}\right)}$

$X_{e}=a \cdot\left(\frac{a_{w}}{1-a_{w}}\right)^{b}$

$X_{e}=k_{1} \cdot a_{w}^{n_{1}}+k_{2} \cdot a_{w}^{n_{2}}$
$X_{e}=\left[-\frac{\ln \left(1-a_{w}\right)}{a}\right]^{1 / b}$

Para este trabalho, levou-se em consideração um bom ajuste matemático dos dados aos modelos estudados o coeficiente de determinação $\left(R^{2}\right)$ próximo à unidade, chiquadrado $\left(X^{2}\right)$ menor valor possível e o erro médio relativo $\left(P_{p}\right)$ abaixo de $10 \%$ (MOHAPATRA e RAO, 2005).

\subsection{Estudo do processo de secagem}

Para o estudo da cinética de secagem das sementes de cevadilha vacariana foi utilizado um secador de bandeja com escoamento paralelo de ar, conforme mostra a Figura 1.

Figura 1 - Secador de leito fixo com escoamento de ar paralelo. (1) Soprador centrífugo, (2) Trocador de Calor, (3) Painel de controle, (4) Balança Digital e (5) Anemômetro de Ventoinha.

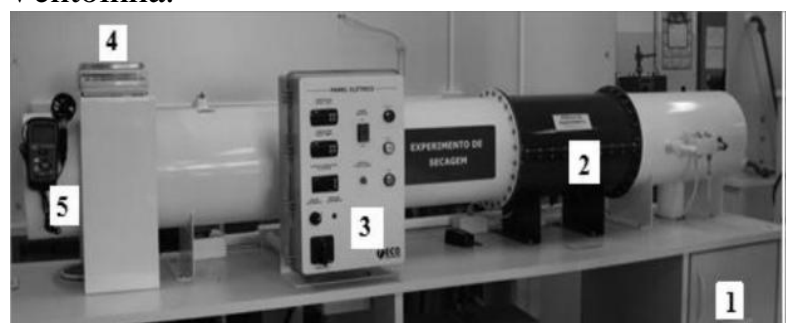

Fonte: Autores (2015).

As variáveis estudadas no processo de secagem foram a temperatura $(T)$ de 40,50 e $60^{\circ} \mathrm{C}$, a velocidade do ar $(v)$ em níveis de 1,0 , 1,5 e $2,0 \mathrm{~m} / \mathrm{s}$ e altura da bandeja $(h)$ nas dimensões de 0,005, 0,0075 e 0,01 m. Sendo esses valores previamente definidos através de revisão na literatura, do qual a partir desses níveis foi desenvolvido um planejamento experimental fatorial $2^{3}$ com tréplica no ponto central, totalizando 11 ensaios de secagem. Nas secagens a carga de sólidos na bandeja variava entre 9 e 16,5 g, conforme altura da bandeja utilizada. Para cada condição estudada, o sistema foi monitorado de 5 em 5 minutos para os primeiros 30 minutos da 
secagem e de 10 em 10 minutos até o sistema alcançar o equilíbrio mássico. As variáveis medidas durante os experimentos foram às temperaturas de bulbo seco (TBS) e temperatura de bulbo úmido $(T B U)$ do ar ambiente, a temperatura do ar de secagem $(T)$ e a massa na bandeja $(m)$. Com os valores da $T B S$ e $T B U$ e com o valor da $T$ do ar de secagem, foi possível caracterizar o ar de secagem através da umidade relativa $(U R)$ e absoluta $(U A)$ antes e após o aquecimento do ar. Para cada experimento realizado, os teores da $U_{B U}$, tanto antes como após o processo de secagem, foram obtidos pelo método recomendado pela AOAC (1997). Também foram determinados as germinações das sementes através da metodologia recomendada pela MAPA/ACS (2009).

\section{RESULTADOS E DISCUSSÃO}

Os resultados obtidos na caracterização física e fisiológica das sementes de cevadilha vacariana fornecidas pela Embrapa - Pecuária Sul são apresentados pela Tabela 1 . Verificase nessa tabela que o valor de $U_{B U}$ obtido encontra-se na faixa indicada (10 a $12 \%$ ) para a comercialização de sementes (Macedo et al., 1987). Os resultados obtidos para $d_{s}, \rho_{r}, \rho_{b}, \varepsilon$, e $\phi$ não foram comparados com a literatura devido à inexistência de dados deste tipo nas bibliografias consultadas. A $G$ da semente de cevadilha vacariana in natura apresentou valor abaixo dos padrões exigidos, o qual estabelece um mínimo de $60 \%$ de sementes germinadas para comercialização, segundo Secretaria da Agricultura do Estado do Rio Grande do Sul (KANNAN, 2015).

Tabela 1 - Resultados da caracterização física e fisiológica das sementes de cevadilha vacariana.

\begin{tabular}{cc}
\hline Propriedade & Valor \\
\hline$U_{B U}(\%)($ secagem natural $)$ & $12,94 \pm 0,119$ \\
$\rho_{r}\left(\mathrm{~kg} / \mathrm{m}^{3}\right)$ & $1415,01 \pm 1,710$ \\
$\rho_{b}\left(\mathrm{~kg} / \mathrm{m}^{3}\right)$ & $375,71 \pm 6,431$ \\
$\varepsilon(-)$ & $0,741 \pm 0,004$ \\
$d_{s}(\mathrm{~mm})$ & $1,710 \pm 0,010$ \\
$\Phi(-)$ & $0,607 \pm 0,002$ \\
$G(\%)$ & $45,67 \pm 1,732$ \\
\hline
\end{tabular}

Fonte: Autores (2015).

A Tabela 2 apresenta os valores dos parâmetros calculados a partir do ajuste dos dados aos modelos de BET, GAB, Oswin, Peleg e Henderson. Também nessa tabela são apresentados os respectivos coeficientes de determinação $\left(R^{2}\right)$, chi-quadrado $\left(X^{2}\right)$ e o erro médio relativo $\left(P_{p}\right)$ para cada modelo utilizado.

Tabela 2 - Valores dos parâmetros encontrados a partir do ajuste dos dados aos modelos de BET, GAB, Oswin, Peleg e Henderson.

\begin{tabular}{ccccc}
\hline Modelo & Valor do parâmetro a $40^{\circ} \mathrm{C}$ & $R^{2}$ & $X^{2}$ & $P_{p}(\%)$ \\
\hline BET & $X_{m}=0,045, c=-1,88 \times 10^{45}, n_{l}=6,903$ & 0,968 & $6,49 \times 10^{-2}$ & 7,284 \\
GAB & $X_{m}=0,060, C t=48,82, K=0,727$ & 0,992 & $8,96 \times 10^{-3}$ & 2,260 \\
Oswin & $a=0,909, b=0,295$ & 0,993 & $9,95 \times 10^{-3}$ & 2,730 \\
Peleg & $k_{l}=0,112, n_{l}=0,368, k_{2}=0,110, n_{2}=5,149$ & 0,992 & $1,16 \times 10^{-2}$ & 2,589 \\
Henderson & $a=160,47, b=2,319$ & 0,974 & $5,93 \times 10^{-2}$ & 6,750 \\
\hline Modelo & Valor do parâmetro a $50{ }^{\circ} \mathrm{C}$ & $R^{2}$ & $X^{2}$ & $P_{p}(\%)$ \\
\hline BET & $X_{m}=0,042, c=-1,13 \times 10^{44}, n_{l}=4,334$ & 0,972 & $3,02 \times 10^{-2}$ & 4,746 \\
GAB & $X_{m}=0,058, C t=45,25, K=0,513$ & 0,982 & $2,37 \times 10^{-2}$ & 3,928 \\
Oswin & $a=0,072, b=0,203$ & 0,971 & $3,24 \times 10^{-2}$ & 4,905 \\
Peleg & $k_{l}=0,192, n_{l}=0,103, k_{2}=0,091, n_{2}=0,700$ & 0,989 & $8,54 \times 10^{-2}$ & 1,675 \\
Henderson & $a=4382,85, b=3,385$ & 0,991 & $1,01 \times 10^{-2}$ & 2,747 \\
\hline
\end{tabular}

Fonte: Autores (2015). 
Tabela 2 - Continuação.

\begin{tabular}{ccccc}
\hline Modelo & Valor do parâmetro a $60{ }^{\circ} \mathrm{C}$ & $R^{2}$ & $X^{2}$ & $P_{p}(\%)$ \\
\hline BET & $X_{m}=0,033, c=9,01 \times 10^{44}, n_{l}=4,382$ & 0,923 & $9,49 \times 10^{-2}$ & 8,398 \\
GAB & $X_{m}=0,051, C t=25,729, K=0,388$ & 0,982 & $1,74 \times 10^{-2}$ & 3,773 \\
Oswin & $a=0,057, b=0,208$ & 0,922 & $1,06 \times 10^{-1}$ & 8,869 \\
Peleg & $k_{l}=0,084, n_{l}=0,435, k_{2}=166,71, n_{2}=1,150$ & 0,988 & $2,13 \times 10^{-2}$ & 3,497 \\
Henderson & $a=6292,43, b=3,233$ & 0,970 & $4,05 \times 10^{-2}$ & 5,475 \\
\hline
\end{tabular}

Fonte: Autores (2015).

De acordo com os valores vistos na Tabela 2, todos os modelos testados representam satisfatoriamente as isotermas de dessorção de semente de cevadilha vacariana, uma vez que todos os modelos obtiveram valores do coeficiente de determinação $\left(R^{2}\right)$ maiores que 0,922 , erro relativo $\left(P_{p}\right)$ abaixo $10 \%$ e chi-quadrado $\left(X^{2}\right)$ menor que $1 \times 10^{-1}$. A partir desses valores o modelo escolhido para representar a curvas de isoterma foi $\mathrm{o}$ modelo de GAB. A escolha procedeu-se devido esse modelo tratar-se de uma equação triparamétrica, além de suas constantes $(C t, K$, $X m)$ representarem significado físico.

Além disso, o modelo de GAB permite um bom ajuste dos dados de sorção de produtos até a atividade de água de 0,90, sendo $C t$ e $K$ constantes de adsorção relacionados com as interações energéticas entre as moléculas da monocamada e as camadas subsequentes, num dado sítio de sorção (PARK, et al., 2007). Os valores destas constantes podem ser um indicativo sobre qual tipo de isotermas que o material analisado corresponde, segundo a classificação Brunauer et al. (1938), onde valores $K<1$ e $C t>2$, podem ser consideradas isotermas do tipo II (PAGLARINI et al., 2013).

O modelo de GAB fornece também os valores de monocamada de água, que indicam a relação com que as reações químicas ocorrem determinando a velocidade de deterioração biológica, através das áreas expostas da matriz sólida. Os valores de umidade da monocamada $\left(X_{m}\right)$ do presente trabalho podem ser considerados coerentes, uma vez que apresentaram uma diminuição de $X_{m}$ com a elevação da temperatura. AlMuhtaseb et al. (2004) e Mclaughlin e Magee (1998), também relataram a diminuição dos valores da monocamada com o aumento da temperatura. Esses autores afirmam que essa tendência é devido a variação do estado de agitação e atração entre as moléculas de água com a variação da temperatura.

Na Figura 2 são apresentadas as curvas experimentais de isotermas de dessorção das sementes de cevadilha vacariana nas temperaturas de estudo, com ajuste dos dados ao modelo de GAB.

Figura 2 - Isotermas de dessorção da Bromus Auleticus T., com ajuste dos dados ao modelo GAB.

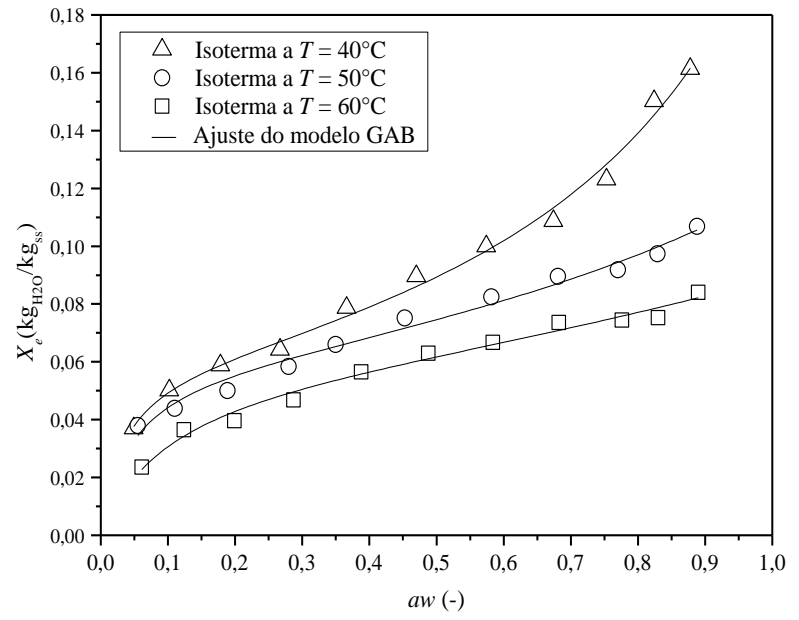

Fonte: Autores (2015).

Através da Figura 2, observa-se que para uma mesma atividade de água, o aumento da temperatura promove uma redução do teor de umidade de equilíbrio, seguindo a tendência da maioria dos produtos 
agrícolas. Este comportamento é geralmente atribuído à uma redução no números de sítios ativos, devido a mudanças químicas e físicas provocada pelo variação da temperatura. Além disso, nota-se que as curvas obtidas para as temperaturas de estudo apresentam um formato sigmoidal, curvas características do tipo II segundo a classificação de Brunauer et al. (1938). Essa classificação informa que esse tipo de isoterma é característica para produtos agrícolas.

Na Figura 3 são apresentadas as curvas do adimensional de água livre em função do tempo para todos os ensaios de secagens realizadas neste estudo.

Figura 3 - Adimensional de umidade livre em função do tempo.

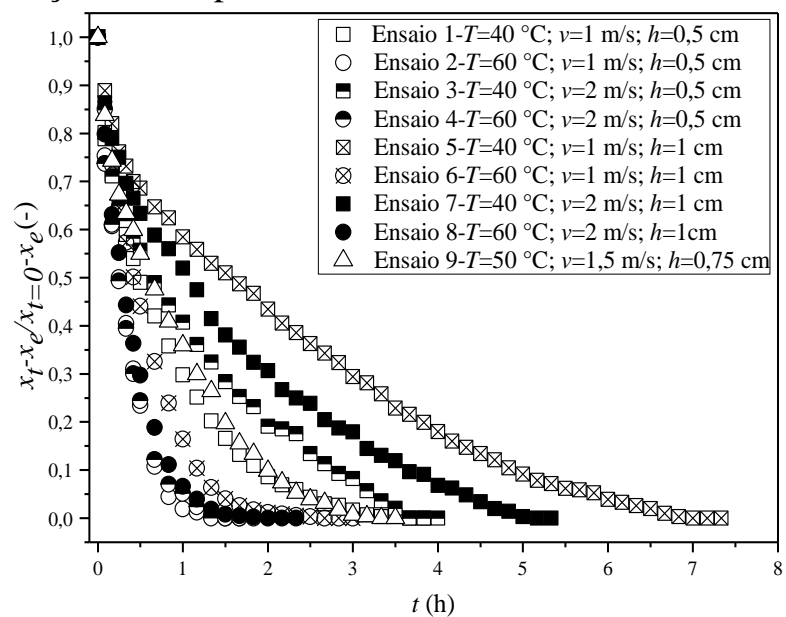

Fonte: Autores (2015).

A partir das curvas da Figura 3 é observado que dentre as secagens, a que teve maior temperatura $\left(60^{\circ} \mathrm{C}\right)$, maior velocidade do ar $(2,0 \mathrm{~m} / \mathrm{s})$ e menor altura de bandeja $(0,5 \mathrm{~cm})$ foi a que apresentou o menor tempo de secagem, com o equilíbrio mássico alcançado em aproximadamente 100 minutos de processo. Já a amostra seca na menor temperatura $\left(40{ }^{\circ} \mathrm{C}\right)$, menor velocidade do ar $(1,0 \mathrm{~m} / \mathrm{s})$ e na maior altura de bandeja $(1,0 \mathrm{~cm})$ foi a que apresentou o maior tempo de secagem, com o equilíbrio mássico sendo atingido em aproximadamente 320 minutos de processo. $\mathrm{O}$ ponto central, equivalente a média dos níveis avaliados, alcançou o equilíbrio mássico em aproximadamente 230 minutos. Para a temperatura e a velocidade do ar de secagem, é observado que o aumento dessas variáveis promoveu uma diminuição do tempo de secagem. Já o aumento da altura de bandeja o processo inverte, ou seja, ocorre um aumento do tempo de secagem. Tal ocorrido pode ser explicado pela física do processo. Uma vez, que a secagem é uma operação que envolve a transferência simultânea de calor e de massa, é esperado que modificações na temperatura do ar, na velocidade do ar e altura de bandeja ocasionem mudanças nos valores das parcelas condutiva e convectiva dos balanços dos fenômenos de transferência para o regime não permanente da secagem. No caso da parcela condutiva, o aumento no valor da temperatura do ar promove uma diminuição na umidade relativa do ar de secagem. Esse fato ocasiona um aumento na diferença de concentração de umidade existente entre o ar de secagem e o material sólido, aumentando assim a força motriz do processo de transferência de massa e uma diminuição no tempo de secagem. Para a parcela convectiva, as mudanças que ocorrem quando a temperatura e a velocidade do ar são alterados podem ser explicadas com base na lei de Newton do resfriamento $\left[\dot{q}^{\prime \prime}=h_{\text {conv }}\left(T_{\infty}-T_{S}\right)\right] . \quad \mathrm{O}$ aumento na temperatura do ar promove um aumento na diferença de temperatura existente entre o ar de secagem $\left(T_{\infty}\right)$ e o material sólido $\left(T_{S}\right)$, aumentando assim a taxa de transferência de calor por convecção $\left(\dot{q}^{\prime \prime}\right)$. Já o aumento na velocidade do ar promove uma elevação no valor do coeficiente de transferência de calor por convecção $(h)$, ocasionando um aumento na taxa de transferência de calor convecção $\left(\dot{q}^{\prime \prime}\right)$. Esse aumento na taxa de transferência de calor por convecção promove um aumento na força motriz do processo e consequentemente uma diminuição no tempo de secagem. Para a altura da bandeja, o aumento da massa de sólidos provoca uma resistência maior ao 
processo de secagem, o que dificulta as transferências de calor e de massa do sistema, provocando assim um aumento no tempo de secagem.

$\mathrm{Na}$ Tabela 3 são apresentados os valores da umidade inicial $\left(U_{\text {inic }}\right)$ e final $\left(U_{\text {secas }}\right)$ em $U_{B U}$, e da germinação $(G)$ das sementes de cevadilha vacariana que passaram pelo processo de secagem nas diferentes condições experimentais estudadas.

Tabela 3 - Respostas dos ensaios de secagem da semente de cevadilha vacariana.

\begin{tabular}{cccc}
\hline Ensaio & $U_{\text {inic }}(\%)$ & $U_{\text {secas }}(\%)$ & $G(\%)$ \\
\hline In & $27,63 \pm 0,37$ & $12,94 \pm 0,02$ & $45,67 \pm 1,53$ \\
natura & $29,17 \pm 0,11$ & $9,14 \pm 1,35$ & $58,00 \pm 2,65$ \\
1 & $28,18 \pm 0,17$ & $4,49 \pm 0,19$ & $27,67 \pm 3,51$ \\
2 & $28,98 \pm 0,24$ & $8,54 \pm 1,40$ & $56,67 \pm 2,52$ \\
3 & $28,26 \pm 0,35$ & $3,92 \pm 0,05$ & $25,00 \pm 3,46$ \\
4 & $28,59 \pm 0,23$ & $9,95 \pm 0,14$ & $55,33 \pm 3,51$ \\
5 & $28,30 \pm 0,12$ & $4,36 \pm 0,19$ & $39,33 \pm 1,15$ \\
6 & $29,16 \pm 0,24$ & $9,37 \pm 0,46$ & $54,67 \pm 4,73$ \\
7 & $28,08 \pm 0,32$ & $3,90 \pm 0,16$ & $27,00 \pm 6,00$ \\
8 & $28,08 \pm 0,12$ & $5,36 \pm 0,37$ & $43,00 \pm 2,00$ \\
9 & $28,15 \pm 0,46$ & $6,69 \pm 1,07$ & $52,67 \pm 5,03$ \\
10 & $27,93 \pm 1,07$ & $5,11 \pm 0,06$ & $54,33 \pm 4,04$ \\
11 &
\end{tabular}

Fonte: Autores (2015).

Observa-se pela Tabela 3 que o aumento no valor da temperatura de $40{ }^{\circ} \mathrm{C}$ (ensaios 1, 3, 5 e 7) para $60{ }^{\circ} \mathrm{C}$ (ensaios 2, 4, 6 e 8) causou uma diminuição no valor da umidade final das sementes de cevadilha vacariana, visto que para todos os ensaios estudados a umidade inicial era de aproximadamente $28 \%$ e após as sementes passarem pelo processo de secagem esses valores ficaram na faixa de aproximadamente 9 e $4 \%$ para os ensaios com a temperaturas de 40 e $60{ }^{\circ} \mathrm{C}$, respectivamente. $\mathrm{Na}$ teoria da secagem, a retirada de umidade da semente ocorre devido a busca pelo equilíbrio termodinâmico entre $\mathrm{o}$ ar circundante e o material sólido (FUMAGALLI, 2007). As modificações na temperatura do ar de secagem causam mudanças na umidade relativa do sistema (atividade de água), logo é esperado que para maiores temperaturas, onde a atividade de água é menor, o valor da umidade final da semente seja inferior ao encontrado em temperaturas mais baixas.

Ainda pela Tabela 3, verifica-se que os valores encontrados para germinação estão na ordem de 25 a $58 \%$ para sementes secas. Já as sementes secas naturalmente a germinação foi de 45,67\%. Dentre as secagens artificiais, a amostra que obteve a maior germinação, com valor de $58 \%$, foi a realizada no ensaio 1 $\left(T=40{ }^{\circ} \mathrm{C}, v=1,0 \mathrm{~m} / \mathrm{s}\right.$ e $\left.h=0,5 \mathrm{~cm}\right)$. Esse valor é superior ao analisado pelo mesmo lote de sementes secas naturalmente e muito próximo do mínimo estabelecido pelas regras de análise de sementes para comercialização, indicando que as secagens em temperaturas mais baixas não alteraram a qualidade fisiológica das sementes.

Para compreender melhor a discussão referente a umidade final e germinação da semente de Bromus auleticus T., são apresentados nas Figuras 4 e 5 os diagramas de pareto referentes aos ensaios de secagens. Nesses diagramas, a magnitude da influência dos efeitos principais e suas interações sobre a resposta umidade final em base úmida $\mathrm{e}$ germinação são apresentadas pelas colunas, enquanto que a linha transversal à coluna representa a magnitude dos efeitos com significado estatístico para $p=0,05$, ou seja, os fatores que são estatisticamente significativos ao nível de $95 \%$ de confiança.

A partir da Figura 4, para a resposta umidade final em base úmida, observa-se que a variável temperatura de secagem $(T)$ foi o fator com significância ao nível de confiança a $95 \%$ que realmente influenciou a resposta $U_{B U}$ final das sementes de cevadilha vacariana. Para este variável, o sinal negativo indica que $o$ aumento na temperatura promoveu uma diminuição no valor da resposta umidade final. Este resultado condiz com as explicações efetuadas na Tabela 3, onde foi constatado que modificações na temperatura do ar de secagem de 40 para 
$60{ }^{\circ} \mathrm{C}$ causaram mudanças na umidade final da semente, logo é esperado que em temperaturas mais elevadas, onde a atividade de água é menor, o valor da umidade do produto final seja inferior ao encontrado em temperaturas mais baixas.

Figura 4 - Diagrama de pareto para estudo da resposta umidade final.

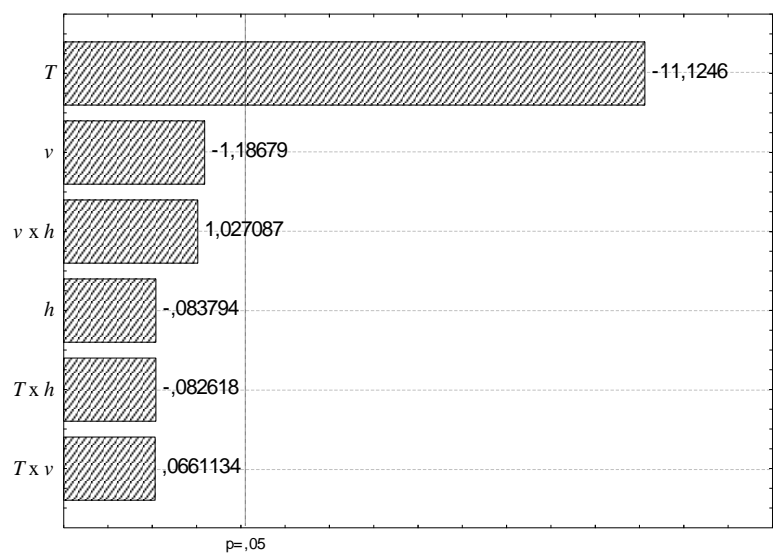

Fonte: Autores (2015).

Figura 5 - Diagrama de pareto para estudo da resposta germinação.

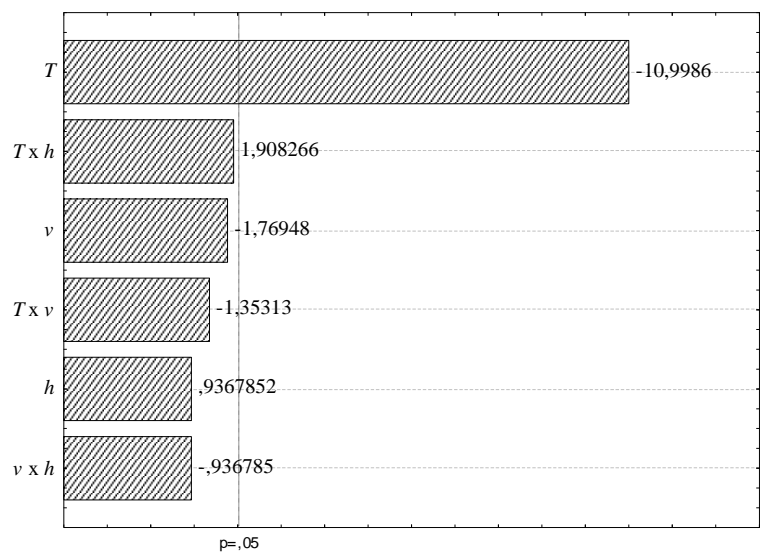

Fonte: Autores (2015).

Pela Figura 5, para a resposta germinação, observa-se que o fator que teve uma magnitude do efeito com significado estatístico para $p=0,05$ também foi a temperatura do ar de secagem. Para essa análise também foi constatado uma magnitude de efeito negativo, resultante do aumento da temperatura do ar de secagem de 40 para
$60{ }^{\circ} \mathrm{C}$, ou seja, a passagem de 40 para $60{ }^{\circ} \mathrm{C}$ promoveu uma diminuição na resposta germinação dos ensaios estudados.

\section{CONCLUSÃO}

$\mathrm{Na}$ caracterização fisiológica das sementes de cevadilha vacariana encontrou-se um valor de germinação das sementes seca in natura de 45,67 \%. Já a caracterização física teve valores para massa específica real de $1415,01 \mathrm{~kg} / \mathrm{m}^{3}$, para massa específica bulk de $365,71 \mathrm{~kg} / \mathrm{m}^{3}$, para porosidade do leito estático de 0,741 , para diâmetro médio de sauter de $1,710 \mathrm{~mm}$ e para esfericidade de 0,607 .

Para a caracterização físico-química através das isotermas de dessorção, foi observado que todos os modelos analisados obtiveram bons ajustes dos seus dados, com elevados $R^{2}$ e baixos $X^{2}$ e $P_{p}$. No entanto o modelo matemático que melhor descreveu o comportamento dos dados nas temperaturas de estudo foi modelo de GAB com coeficientes de determinação entre 0,982 e 0,992 , chi-quadrado entre $8,96 \times 10^{-3}$ e $1,74 \times 10^{-2}$ e erro médio relativo entre 2,260 e $3,928 \%$. As curvas experimentais de isoterma de dessorção das sementes de cevadilha vacariana apresentaram formato sigmoidal referentes ao tipo II da classificação de Brunauer et al. (1938).

$\mathrm{Na}$ avaliação das curvas do adimensional de umidade em função do tempo conclui-se que o aumento na temperatura e na velocidade do ar de secagem acarreta um aumento na força motriz de secagem, consequentemente diminuem o tempo do processo. Para análise da altura da bandeja, observa-se o processo inverso, ou seja, o aumento da massa de sólidos dificulta o processo de transferência de massa, e consequentemente há um aumento no tempo de secagem.

Em relação à análise de umidade final, conclui-se que temperatura foi a variável de 
maior influencia nas sementes de Bromus auleticus T. Para germinação das sementes de cevadilha vacariana, constata-se que as sementes secas tiveram boa representação para as temperaturas de 40 e $50{ }^{\circ} \mathrm{C}$ e baixos valores de germinação para as temperaturas de $60{ }^{\circ} \mathrm{C}$.

\section{NOMENCLATURA}

\begin{tabular}{|c|c|c|}
\hline$a_{w}$ & atividade de água & {$[-]$} \\
\hline $\begin{array}{l}a, b, c, C t, K, \\
k_{1}, k_{2}, n_{1} e n_{2}\end{array}$ & $\begin{array}{c}\text { constate dos } \\
\text { modelos }\end{array}$ & {$[-]$} \\
\hline $\mathrm{G}$ & germinação & [\%] \\
\hline$d_{s}$ & $\begin{array}{c}\text { diâmetro de } \\
\text { sauter }\end{array}$ & [L] \\
\hline$h$ & altura da bandeja & [L] \\
\hline$T$ & temperatura & {$[\theta]$} \\
\hline$T B S$ & $\begin{array}{c}\text { temperatura de } \\
\text { bulbo seco }\end{array}$ & {$[\theta]$} \\
\hline$T B U$ & $\begin{array}{l}\text { temperatura de } \\
\text { bulbo úmido }\end{array}$ & {$[\theta]$} \\
\hline$U_{B U}$ & $\begin{array}{c}\text { umidade em base } \\
\text { úmida }\end{array}$ & {$\left[\mathrm{MM}^{-1}\right]$} \\
\hline$U_{\text {inic }}$ & $\begin{array}{l}\text { umidade inicial } \\
\text { das sementes }\end{array}$ & {$\left[\mathrm{MM}^{-1}\right]$} \\
\hline$U_{\text {secas }}$ & $\begin{array}{c}\text { umidade das } \\
\text { semente secas }\end{array}$ & {$\left[\mathrm{MM}^{-1}\right]$} \\
\hline$v$ & velocidade do ar & {$\left[\mathrm{MT}^{-1}\right]$} \\
\hline$X_{m}$ & $\begin{array}{c}\text { umidade de } \\
\text { monocamada }\end{array}$ & {$\left[\mathrm{MM}^{-1}\right]$} \\
\hline$X_{e}$ & $\begin{array}{l}\text { umidade de } \\
\text { Equilíbrio }\end{array}$ & {$\left[\mathrm{MM}^{-1}\right]$} \\
\hline$X_{t}$ & $\begin{array}{l}\text { umidade no } \\
\text { tempo inicial }\end{array}$ & {$\left[\mathrm{MM}^{-1}\right]$} \\
\hline$X_{t 0}$ & $\begin{array}{l}\text { umidade no } \\
\text { tempo inicial }\end{array}$ & {$\left[\mathrm{MM}^{-1}\right]$} \\
\hline$\varepsilon$ & porosidade & {$[-]$} \\
\hline$\rho_{b}$ & $\begin{array}{c}\text { massa específica } \\
\text { bulk }\end{array}$ & {$\left[\mathrm{ML}^{-3}\right]$} \\
\hline$\rho_{r}$ & $\begin{array}{c}\text { massa específica } \\
\text { real }\end{array}$ & {$\left[\mathrm{ML}^{-3}\right]$} \\
\hline$\phi$ & esfericidade & {$[-]$} \\
\hline
\end{tabular}

\section{REFERÊNCIAS}

AOAC, Association of Oficial Analytical Chemists. Official methods of analysis. 16th ed.Washington D.C.: AOAC, v.2, 1997.

AL-MUHTASEB, A. H.; McMINN, W. A. M.; MAGEE, T. R. A. Water sorption isotherms of starch powders Part 1: mathematical description of experimental data. Journal of Food Engineering, v.61, p.297-307, 2004.

BRUNAUER, S.; EMMETT, P. H.; TELLER, E. Adsorption of gases in multimolecular layer. Journal of American Chemistry Society. v. 60, p. 309-312, 1938.

CARVALHO, N. M. A secagem de sementes. Jaboticabal: FUNEP, 165p, 1994.

FUMAGALLI, F.; Estudo da transferência de calor e massa na secagem das sementes de Brachiária brizantha.2007. 3-73p. (Tese Doutorado em engenharia química). Universidade Federal de São Carlos, São Carlos, 2007.

KANAAN, A. F.; FLORES, C. G.; OLIVEIRA, J. C. P.; ALMEIDA, A. R. F. Secagem de cornichão (Lotus corniculatus 1.) em leito fixo com escoamento de ar paralelo. In: Anais do XX Congresso Brasileiro de Engenharia Química - COBEQ 2014 [ Blucher Chemical Engineering Proceedings, v.1, n.2]. São Paulo: Blucher, 2015. p. 6178-6185.

KARATHANOS, V. KANELLOPOULOS, N. K., BELESSIOTIS, V. G., 1996. Development of porous structure during airdrying of agricultural plant products. Journal of Food Engineering, v.29, 167-183, 1996. 
MACEDO, G. A. R.; MARQUES NETO, J. E.; BATISTA, J. S. Secagem à sombra e ao sol de sementes de gramíneas forrageiras. Revista Brasileira de Sementes, n.3, p.2937, 1987.

MAPA, Ministério da Agricultura, Pecuária e Abastecimento. Regra para Análises de Sementes. Ministério da Agricultura, Pecuária e Abastecimento. Secretaria de Defesa Agropecuária-Brasília:Mapa/ACS, p. 399, 2009.

McLAUGhlin, C. P.; MAGEE, T. R. A. The determination of sorption isotherm and isosteric heats of sorption for potatoes. Journal of Food Engineering. v.13 n.35, p.267-280, 1998.

MIRANDA, L. C.; SILVA, da W. R.; CAVARIANI, C. Secagem de sementes de soja em silo com distribuição radial do fluxo de ar. I. Monitoramento físico. Pesquisa agropecuária brasileira, v.34, n.11, p.20972108, 1999.

MOHAPATRA, D.; RAO, P. S. A thin layer drying model of parboiled wheat. Journal of Food Engineering, v.66, p.513-518, 2005.

NABINGER, C. Manejo e produtividade das pastagens nativas do subtrópico brasileiro. In:Anais Simpósio de forrageiras e produção animal, 1, Porto Alegre: UFRGS, 2006. p.25-76.

OLIVEIRA, J. C. P.; MORAES, C. O. C. Distribuição da Produção e qualidade de forragem de Bromus auleticus Trinius. Revista de Pesquisa Agropecuária Brasileira, v.28, n.3, p.391-398, 1993.

PAGLARINI, C. de S.; da SILVA F. S.; PORTO, A. G.; Piasson, D.; dos SANTOS, P. Histerese das isotermas de sorção da polpa de manga (Mangifera indica L.) variedade manteiga. Revista Brasileira de Engenharia Agrícola e Ambiental. v.17, n.3, p.299-305, 2013

PARK, K. J.; ANTONIO, G. C.; OLIVEIRA, R. A.; PARK, K. J. B. Conceitos de processo e equipamentos de secagem. Campinas-SP, p.17-84, 2007.

PESKE. S; ROSENTHAL. M; ROTA. G. R. Sementes: fundamentos científicos e tecnológicos. Pelotas - RS, p. 282, 2003.

\section{AGRADECIMENTOS}

Os autores deste trabalho agradecem a UNIPAMPA/Bagé e EMBRAPA/Pecuária Sul pela infraestrutura disponibilizada e a CAPES pela concessão da bolsa. 